\title{
Main constructive diagenesis of middle-lower Ordovician of Yubei Area in Tarim Basin
}

\author{
Zhao Hanting ${ }^{1, a}$, Fan Tailiang ${ }^{1, b}$ \\ 1,Key Laboratory for Marine Reservoir Evolution and Hydrocarbon Accumulation Mechanism, \\ Ministry of Education of China, China University of Geosciences, Beijing 100083, China \\ aibwinibwin@hotmail.com, ${ }^{\text {}}$ fantl@cugb.edu.cn
}

Keywords: Yubei area;Tarim;Ordovician;Diagenesis;

Abstract.According to analysis of cores, rock sections, casting sections, logging data of Ordovician carbonate reservoirs in the Yubei area,reservoir rock in the study area include 4 types:mud micrite limestone,grain limestone,biological limestone and dolomitic limestone.In combination with core photos and imaging logging analysis, reservoir can be divided into pores and cracks.Diagenesis mainly includes compaction, pressolution, cementation, filling, recrystallization, dolomitization, dissolution .To sum up, the main constructive diagenesis include recrystallization, dolomitization, dissolution,otherwise the main destructive diagenesis include compaction, pressolution, cementation, filling.

\section{Introduction}

Yubei area is located in the eastern maigaiti slope of tarim basin, whose northern border is bachu uplift Mazhatage fault zone, eastern border extends to Tangguzibasi sag, and southern border yecheng - hetian sag of south-western depression. The ordovician strata distribution is complex, by means of Yubei No.1 NE fault zone, it can be divided into three small unit, namely the western Yubei platform area, NE structural belt and Yudong fault depression zone (Figure 1). NE and nearly EW fracture and local structures developed very well in the area. Well Yubei 1 lies on NW fault zone, which shows "Y" shape.Multiple fault anticline traps developed in the top of the ordovician yingshan formation, which developed in middle -late caledonian and late hercynian ${ }^{[1-2]}$.

In recent years,along with the deepening of exploration, there are more researches to discuss the characteristics and genetic analysis of the ordovician reservoir in Tarim basin, putting forward a variety of the main controlling factors of diagenesis ${ }^{[3-5]}$. On the basis of a large number of core observation and thin section identification, using of the geochemical data, author probes into the ordovician diagenesis of this area, so as to provides the basis for exploration and development.

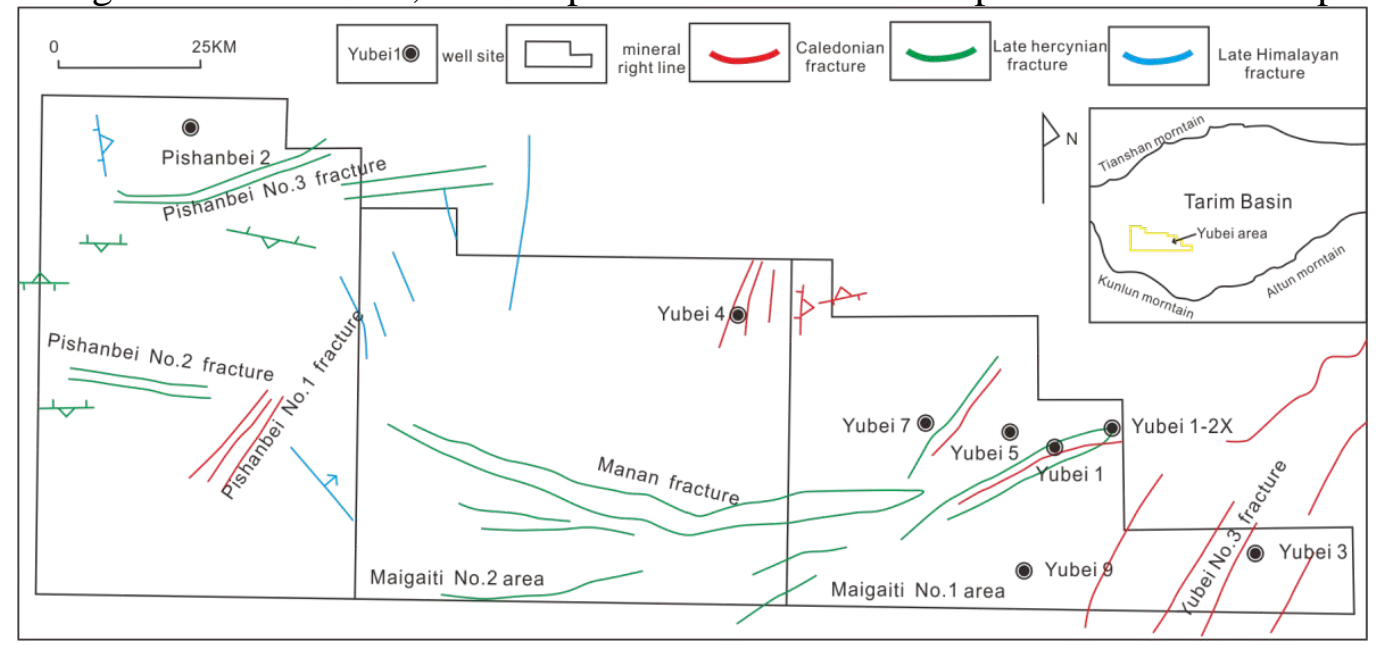

Fig.1 Tectonic location of Yubei area in Tarim Basin 


\section{Main diagenesis}

There are various types of diagenesis. It includes cementation,dissolution, compaction and pressolution, dolomitization, filling and recrystallization ${ }^{[6-10]}$.

\subsection{Dissolution}

The ordovician carbonate reservoir has experienced three periods of dissolution, respectively, penecontemporaneous atmospheric dissolution, burial dissolution and supergene karst dissolution, especially the supergene karst dissolution and burial dissolution was the most of importance.

a.penecontemporaneous atmospheric dissolution.

It mainly happened just from deposition to shallow burial stage, forming selective dissolution pore,such as intragranular pore, mold pore and intergranular dissolved pore.The identification marks in the study area are:in the sparry oolitic and calcarenite, fibre shape calcite cement were partly or completely dissolution, and the residual fiber calcite and the next phase granular calcite show unconformity contact. (FIG. 2-1).

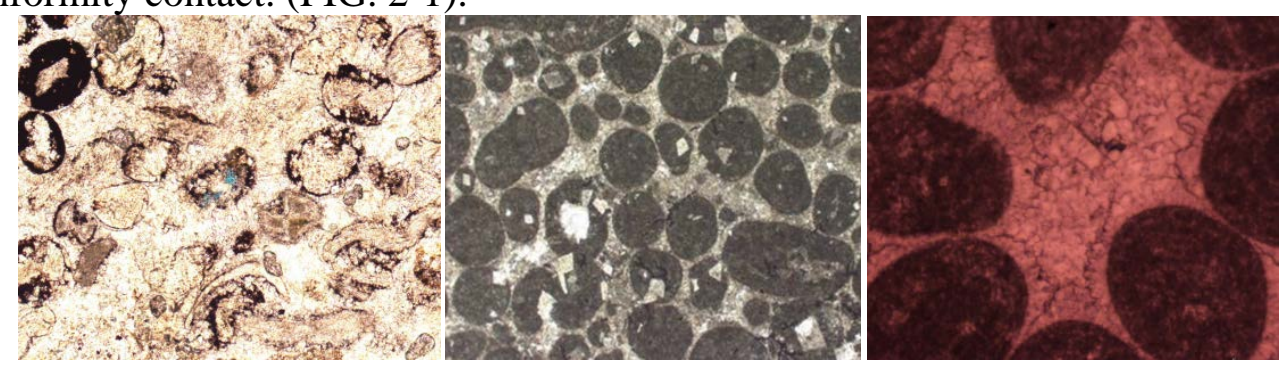

Well Pishanbei2,6898.94m, $\mathrm{O}_{3} \mathrm{l}$, sparry granular-clast limestone Well YB4,5900.88m, $\mathrm{O}_{3} \mathrm{l}$, sparry oolitic limestone Well YB4 井,5838.6m, $\mathrm{O}_{3} \mathrm{l}$, sparry oolitic limestone

Fig.2-1 atmospheric dissolution characteristics

b. Burial dissolution

Burial dissolution is not selective which developed inter-grain pores, intergranular dissolved pore, soluble seam along suture lines, etc. its identification marks are(FIG. 2-2): (1) harbor shaped edge;(2) within the dolomite intracrystalline hole and siliceous dissolved pore, filling black bituminous and black carbonaceous bitumen also visible in edge;(3) bitumen also visible in solution pores around the suture line;

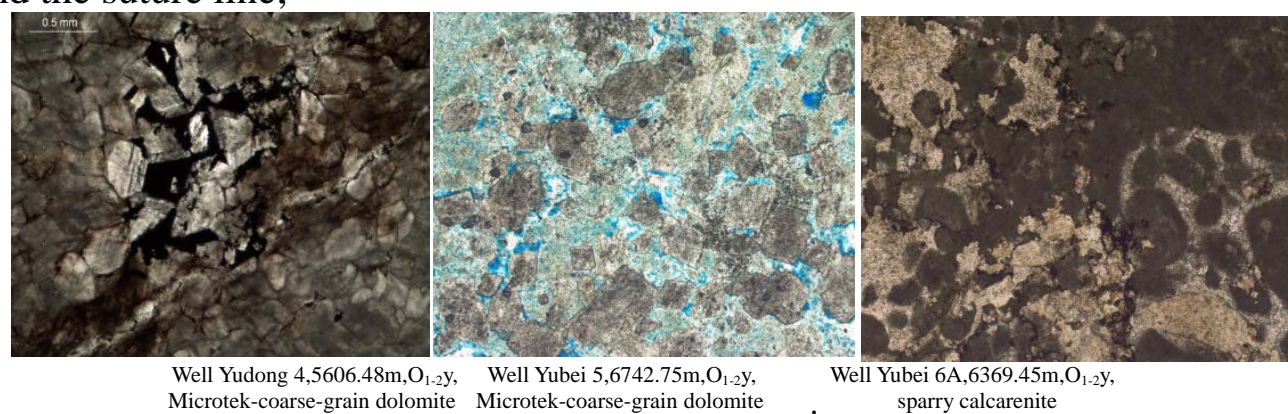

Fig.2-2 burial dissolution characteristics

c.Supergene karst dissolution

Its identification marks (FIG. 2-3) : (1) pyrites occurred ferritization;(2) iron oxide visible within the sutures and microfracture;(3) shale along the suture line corrosion. 

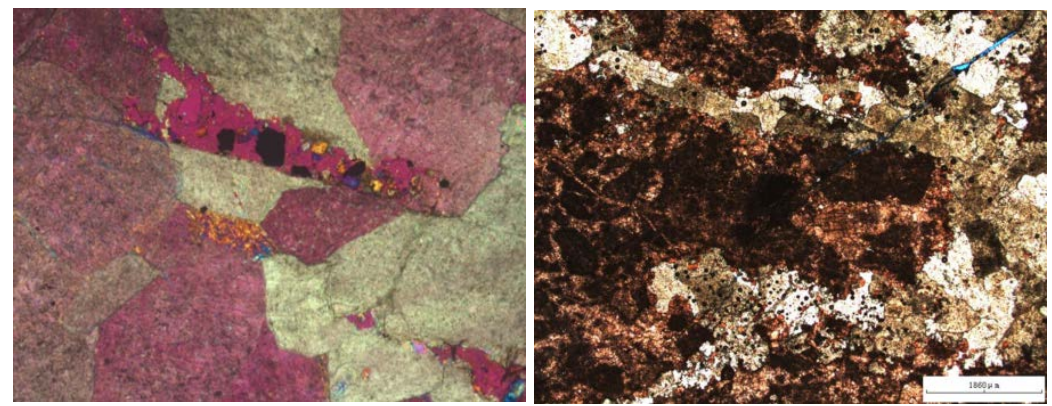

Well Yubei 3,5367.65m, $\mathrm{O}_{1-2} \mathrm{y}$, sparry alga-gobbet dolomitic limestone. without filling or filled by calcite, ferreous mud structural fractures $(-) \times 16$

Well Yubei 3,5317m,O1-2y, Intergranular dissolved pore filled by silt sand, hematite, argillaceous

Fig.2-3 Supergene karst dissolution characteristics

\subsection{Dolomitization}

dolomitization occurs mainly on the top of yingshan formation in the fault zone and the bottom of yingshan formation-penglaiba formation in the whole Yubei region. It can be divided into pene-sedimentary dolomitization and burial dolomitization.

(1) penecontemporaneous dolomitization

Penecontemporaneous dolomitization mainly forms the layer micritic dolomite, arene mud - powder crystal dolomite with better crystal shape, mainly from idiomorphism, hypidiotopic crystal (FIG. 2-4).

(2) burial dolomitization

The burial dolomitization is the most common dolomitization in Yubei region. The grain is relatively bulky, microtek - coarse grain;Crystal shape is mainly idiomorphism, hypidiotopic, with a inlay contact between grains, apparent wavy extinction, fog heart and bright edges, metasomatism and burial, recrystallization characteristics. The burial dolomitization is common on the top of yingshan formation, the bottom of yingshan formation-penglaiba formation in fault zone; very rare on Lianglitage formation-Yijianfang formation (FIG. 2-5).

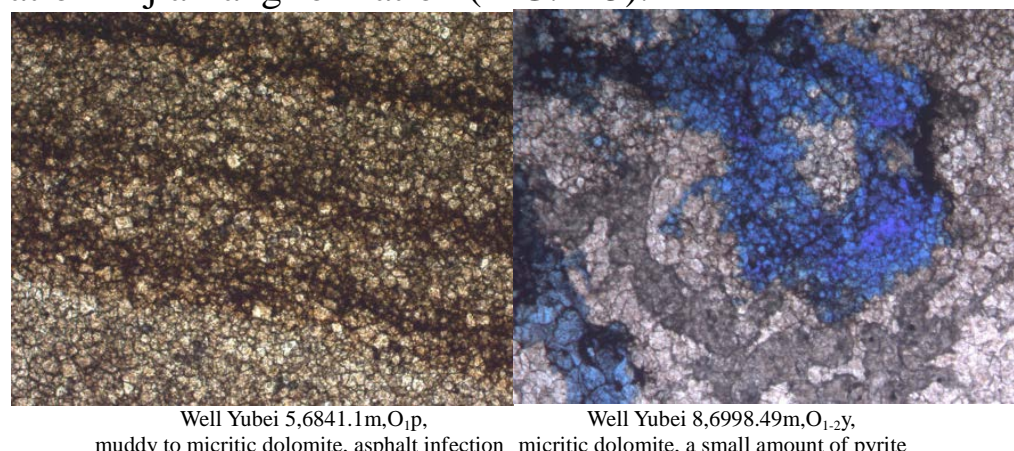

Fig.2-4 penecontemporaneous dolomitization characteristics in Yubei area

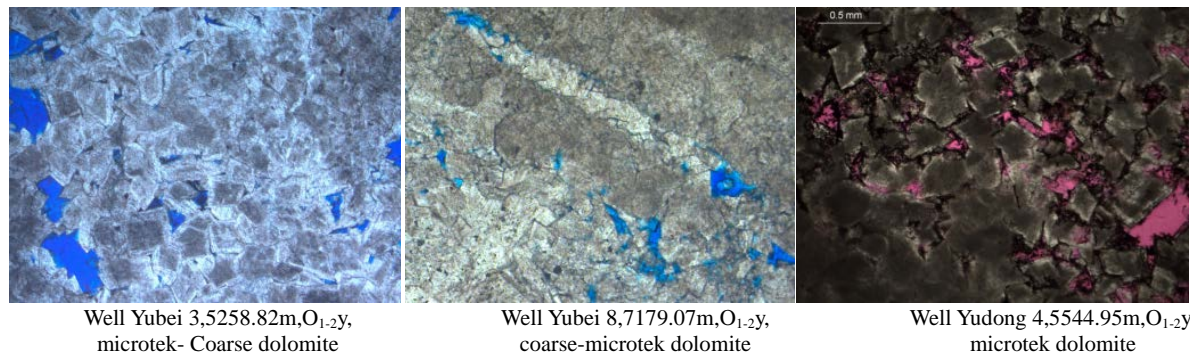

Fig.2-5 burial dolomitization characteristics in Yubei area

\subsection{Recrystallization}

Recrystallization in Yubei areas are also more common constructive diagenesis. In the bottom of yingshan formation-penglaiba formation,it is common, showing the mud - powder crystal recrystallization formed fine microtek dolomite, partially recrystallization into coarse grain 
dolomite, and mineral structure be thicker, throat also be more smooth and flat and intercrystalline pore increasing, providing more conducive to later dissolution channels, forming more intergranular pore and intergranular dissolved pore.Recrystallization cannot form a large storage space, but it can improve the original microscopic pore structure of rock.According to 47 casting microvoid structure in Yubei area, dolomite intercrystal pore, intergranular dissolved pore rate was 4\%(FIG. 2-6).

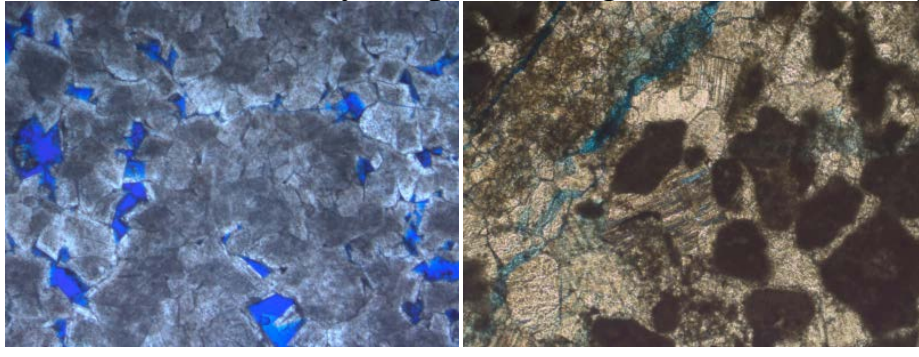

Well Yudong 4,5545.16m, microtek dolomite, Well Yubei 6A, 6375.63m, sparry calcarenite the intergranular hole, intergranular dissolved pore limestone, local micritic recrystallization, $\times 30$

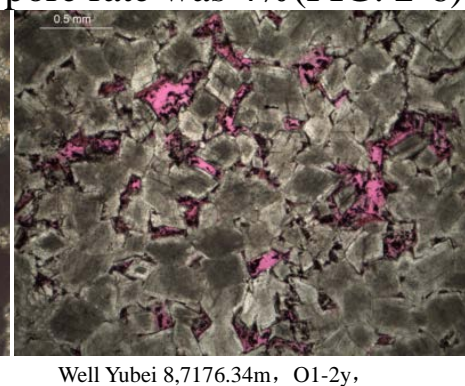

Fig.2-6 Recrystallization characteristics in Yubei area

\section{Conclusion}

According to the study above, the constructive diagenesis includes dissolution,dolomitization and recrystallization.It is very important for the study area to further exploration.

Fund Program: 2011ZX05005-002-010HZ The sequence structure restriction to diagenesis of reservoir in Tarim basin

\section{Reference}

[1]Zhang Zhongpei,Liu Shilin,Yang Ziyu,et al.Tectonic evolution and its petroleum geological significances of the Maigaiti Slop,Tarim Basi[J].Oil \& Gas Geology,2011,32(6) : 909-918.

[2]Qiao Guilin,Qian Yixiong,Cao Zicheng,et al. Reservoir characteristics and karst model of Ordovician

Yingshan Formation in Yubei area,Tarim Basin[J]. Petroleum Geology \& Experiment,2014,36(4):416-428.

[3] Yang Haijun, Han Jianfa, Sun Chonghao, et al. A development model and petroleum exploration of Karst reservoirs of Ordovician Yingshan Formation in the northern slope of Tazhong palaeouplift[J].Acta Petrolei Sinica, 2011, 32(2): 199-205.

[4] Han Jianfa, Mei Lianfu, Yang Haijun, et al. The study of hydrocarbon origin, transport and accumulation in Tazhong area,Tarim Basin [J]. Natural Gas Geoscience, 2007, 18 (3):426-435.

[5] Wang Zhaoming, Zhao Kuanzhi, Wu Guanghui, et al. Characteristics and main controlling factors of the Upper Ordovician reef-bank reservoir development in the Tazhong I slope-break zone[J]. Oil \& Gas Geology, 2007, 28(6): 797-801.

[6] Wang Zhaoming, Wang Qinghua, Wang Yuan. Conditions and controlling factors of hydrocarbon accumulation of Hetianhe Gas Field, Tarim Basin[J]. Marine Origin Petroleum Geology, 2000,5(1/2): 124-132.

[7] Lizhong,Huang Sijing,Liu Jiaqing,et al. Buried diagenesis, structurally controlled thermal fluid process and their effect on ordovician carbonatereservoirs in Tahe, Tarim Basin[J]. Acta Sendimentology sinaca,2010,28(5):969-979.

[8] Luo Chunshu, Yang Haijun, Li Jianghai, et al. Characteristics of high quality Ordovician reservoirs and controlling effects of faults in the Tazhong area, Tarim Basin[J]. Petroleum Exploration and Development, 2011, 38(6): 716-724.

[9] Wang Zhenyu,Yang Liuming,Mafeng,et al. Origin of dolomite of Lower Ordovician Yingshan 
Formation in Tazhong area[J]. Lithologic Reservoirs,2012,24(2):21-23.

[10] Zhang Nai, Zhao Zongju, Xiao Zhongyao, et al. Characteristics of hydrocarbon fluid in the Ordovician vein calcite of Tazhong No.1 slope-break zone[J]. Natural Gas Geoscience, 2010, 21(3):389-396. 